\title{
Reactivation of resolved hepatitis B virus infection combined with nephrotic syndrome in a patient after allogeneic haematopoietic stem cell transplantation
}

\author{
Jing-Wen Zhang ${ }^{\dagger}$, Xiang-Zhong Zhang ${ }^{\dagger}$, Yan-Ling Sun, Bing Long, Xiao-Zhen Wang and Xu-Dong Li ${ }^{*}$
}

\begin{abstract}
Background: After allogeneic haematopoietic stem cell transplantation (allo-HSCT), Hepatitis B virus reactivation $(\mathrm{HBV} r$ ) can be observed in patients with previous resolved Hepatitis B virus (HBV) infections. Nephrotic syndrome (NS) is the main clinical manifestation of HBsAg-positive glomerulonephritis. However, the development of HBVr combined with NS after allo-HSCT is uncommon.

Case presentation: We presented a case of a 47-year-old female with acute myelogenous leukemia who underwent HLA-identical sibling allo-HSCT and achieved leukemia free survival. She had pretransplant serological markers of a resolved HBV infection (HBsAg-negative, anti-HBC and anti-HBs positive). However, she developed HBVr combined with nephrotic syndrome (NS) 16 months after HSCT. Her histological renal lesion was mesangial proliferative glomerulonephritis. IgA+, lgM+, and C1q deposits but not HBV antigens (HBsAg and $\mathrm{HBCAg}$ ) were identified in her renal biopsy material. Long-term entecavir and immunosuppression resulted in decrease of HBV virus replication, amelioration of proteinuria and stabilisation of renal function.

Conclusions: Entecavir combined with immunosuppression has efficacy in the treatment of HBVr combined with NS after allo-HSCT, but long course of treatment is needed. Closely monitoring and antiviral prophylaxis might be necessary for allo-HSCT recipients to prevent reactivation of resolved HBV infection and its related complications.
\end{abstract}

Keywords: Hepatitis B virus, Reactivation, Nephrotic syndrome, Haematopoietic stem cell transplantation, Immunosuppression

\section{Background}

Hematopoietic stem cell transplantation (HSCT) is broadly undertaken with the aim of a complete cure of hematopoietic malignancies. Hepatitis B virus reactivation (HBVr) after allogeneic haematopoietic stem cell transplantation (allo-HSCT) is well known in HBsAg-positive carriers but has only occasionally been reported in patients with resolved Hepatitis B virus (HBV) infection [1, 2]. Resolved HBV infection is defined as follows: Previous known history of acute or chronic hepatitis B or the presence of anti-HBc with/without anti-HBs; HBsAg negative; undetectable

\footnotetext{
* Correspondence: lixudong_sysu@sina.com

† Jing-Wen Zhang and Xiang-Zhong Zhang contributed equally to this work Department of Hematology, The Third Affiliated Hospital, Sun Yat-sen University, 600 Tianhe Road, Guangzhou, China
}

serum HBV DNA; normal aminoleucine transferase (ALT) levels [3]. Recovery from an acute infection is usually assumed to provide lifelong protection against a future exposure to HBV. However, in individuals with resolved infection, HBV has been shown to persist in a 'latent' state in the liver and in peripheral blood mononuclear cells for years and possibly even lifelong [4]. With severe immunosuppression, HBsAg may reappear (reverse seroconversion) or viral replication may be detectable.

Renal dysfunction after HSCT is common. But the development of nephrotic syndrome (NS) after HSCT is uncommon and the incidence rate was reported to be $0.37-1.03 \%$ in adults [5]. Renal injury may also occasionally occur in patients with HBV infection and the incidence rate was about 3\% [6]. The authors describe here

(c) The Author(s). 2019 Open Access This article is distributed under the terms of the Creative Commons Attribution 4.0 International License (http://creativecommons.org/licenses/by/4.0/), which permits unrestricted use, distribution, and reproduction in any medium, provided you give appropriate credit to the original author(s) and the source, provide a link to the Creative Commons license, and indicate if changes were made. The Creative Commons Public Domain Dedication waiver (http://creativecommons.org/publicdomain/zero/1.0/) applies to the data made available in this article, unless otherwise stated. 
a rare case with evidence of resolved HBV infection developed $\mathrm{HBVr}$ combined with NS after allo-HSCT.

\section{Case presentation}

A 47-year-old female came to our hospital with a 20-day history of gingival bleeding and skin ecchymosis in September, 2014. Complete blood count showed leukocyte count $2,187,000 / \mathrm{mm}^{3}$, hemoglobin $8.6 \mathrm{~g} / \mathrm{dL}$, and platelet count $54,000 / \mathrm{mm}^{3}$. A bone marrow aspiration revealed $30 \%$ myeloblast. Chromosome analysis revealed $11 \mathrm{q} 23$ abnormality. An MLL-AF6 fusion transcript was detected by a reverse transcriptase polymerase chain reaction (RT-PCR). A diagnosis of acute myelogenous leukemia with 11q23/MLL translocations (high risk) was made. She entered remission after induction chemotherapy with idarubicin and cytarabine. She subsequently received two courses consolidation therapy with high dose cytarabine and one course of consolidation therapy with mitoxantrone and cytarabine. Then she underwent HLA-identical sibling HSCT in January, 2015. Conditioning include cytarabing, busulfan, semustine and cyclophosphamide. Graft-versus-host (GVHD) prophylaxis consisted of cyclosporine, methotrexate, and mycophenolate mofetil. Immunosuppression was tapered and then discontinued on September 17, 2015. She achieved trilineage engraftment and leukemia-free survival.

From onset to pretransplantation, monthly monitoring of HBV-related serum markersall showed that anti-HBs and anti-HBc were positive, HBsAg was negative, serum HBV DNA was undetectable, alanine aminotransferase (ALT) and aspartate aminotransferase (AST) were normal (below $40 \mathrm{IU} / \mathrm{L}$ ). Her donor serology showed no previous HBV infection (HbsAg, anti-HBc and anti-HBs negative). The patient received entecavir at a dose of $0.5 \mathrm{mg}$ once daily to prevent HBV reactivation and discontinued simultaneously with the cessation of immunosuppression in September 2015. In December 2015, laboratory tests showed serum transaminase levels were increased (AST 146 IU/L, ALT $163 \mathrm{IU} / \mathrm{L}$ ), serum anti-HBs and anti-HBc turned negative, HBsAg was still negative and the HBV DNA titer was undetectable, and her renal function was normal. Liver chronic GVHD was considered and methylprednisolone was administered $(8 \mathrm{mg} / \mathrm{d}$ for 10 days then $4 \mathrm{mg} / \mathrm{d}$ for a month). Then her serum transaminase levels returned to normal. She was then discharged from the hospital and told to monitor HBV-related serum markers and liver function monthly. But she did not have follow-up examinations in our out-patient clinic.

In May 2016, she presented to our hospital with moderate edema of both lower limbs and foamy urine for half a month. Her renal function was impaired (creatinine, $112 \mathrm{umol} / \mathrm{L}$ ), and NS was confirmed by low serum albumin $(19.0 \mathrm{~g} / \mathrm{L})$, high cholesterol $(10.21 \mathrm{mmol} / \mathrm{L})$, and proteinuria (11.3 g/day). Detection of HBV-related serum markers showed that HBsAg and HBeAg turned positive, and the quantity of HBV DNAwas $1.7 \times 10^{8} \mathrm{IU} / \mathrm{ml}$. ALT and AST were still normal. Her liver and kidneys appeared normal on ultrasound examination. Two kidney biopsies containing 34 glomeruli were analysed morphometrically. Light microscopy revealed 4 glomeruli $(11.7 \%)$ were completely collapsed; the rest mesangial areas were slightly to moderately widened, with glomerular mesangial cells proliferation and extracellular matrix accumulation; chronic tubulointerstitial damages existed, including focal tubular atrophy, tubular epithelial brush-border loss, focal interstitial fibrosis and monocytes infiltration; the capillary loops were open and there was no thickening of the glomerular basement membrane(Fig. 1). Immunofluorescence revealed deposits in segmental glomerular capillary loops and mesangial area; sample fluorescence distribution: IgA+; IgM+; C1q+, IgG-, C3-, HBsAg-, HBcAg-. Kidney pathology was consistent with mesangial proliferative glomerulonephritis.

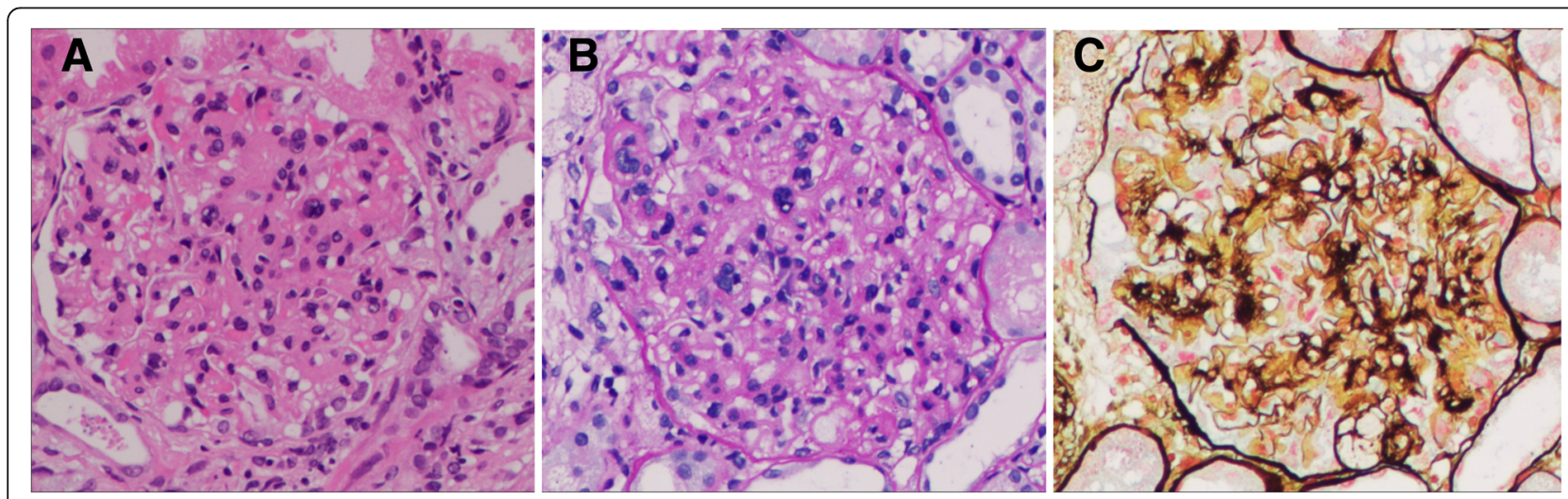

Fig. 1 Image of renal biospy. The mesangial areas were slightly to moderately widened, with glomerular mesangial cells proliferation and extracellular matrix accumulation. (a HE staining, b PAS staining, c silver staining, 400x) 
She was immediately administered entecavirat a dose of $0.5 \mathrm{mg}$ once daily to repress the replication of $\mathrm{HBV}$ DNA and valsartan at a dose of $800 \mathrm{mg}$ once daily to reduce urinary protein. Two months later, the level of HBV DNA decreased to $2.4 \times 10^{4} \mathrm{IU} / \mathrm{ml}$. However, her renal function was still aggravated. The level of serum albumin was $16.5 \mathrm{~g} / \mathrm{L}$ and creatinine was 125 umol/L. Then immunosuppressive therapy was started to treat kidney disease. Mycophenolate mofetil at a dose of 500 $\mathrm{mg} / 12 \mathrm{~h}$ and prednisone at a dose of $20 \mathrm{mg} / \mathrm{d}$ were initiated and then gradually reduced. Her renal function was gradually improved. In April 2017, her serum albumin was $42.2 \mathrm{~g} / \mathrm{L}$ and serum creatinine was $84 \mathrm{umol} / \mathrm{L}$. But her urine albumin creatinine ratio was $844.13 \mathrm{mg} / \mathrm{g}$ and the quantity of HBV DNA was $9.5 \times 10^{2}$ copies $\mathrm{IU} / \mathrm{ml}$, which meant she still had clinical albuminuria and persistent HBV replication. In July 2018, she was given mycophenolate mofetil at a dose of $500 \mathrm{mg} / \mathrm{d}$ and prednisone at a dose of $8 \mathrm{mg} / \mathrm{d}$, and her urine albumin creatinine ratio declined to $48.57 \mathrm{mg} / \mathrm{g}$. She continued to be treated with immunosuppressive therapy and antiviral therapy.

\section{Discussion and conclusions}

According to previous reports, NS develops on average approximately 1 to 2 years after allo-HSCT [5, 7]. Its etiology may be related to drug toxicity, infection, or graft versus host disease (GVHD) [8]. In our case, the patient developed NS 16 months after transplantation and 8 months after the cessation of immunosuppression, so the etiology could not be drug toxicity.

NS has been reported to be a manifestation of chronic GVHD (cGVHD) [9, 10]. However, the incidence of NS associated with cGVHD is rare. GVHD as the definitive cause of the nephropathy should be interpreted with caution. GVHD-related NSwas considered present according to the following points: the development of NS immediately after the discontinuation or a dosage decrease of immunosuppression therapy, lymphocyte infiltration observed in the kidney, and the existence of other manifestations of cGVHD [10, 11]. However, in our case, NS was developed 6 months after the cessation of immunosuppression therapy; the patient had no manifestations of cGVHD in other organs; and lymphocytes infiltration was not observed in the kidneys. Therefore, there was no enough evidence to prove that the kidneys were the target of cGVHD.

This patient had a history of resolved HBV infection (HBsAg-negative, anti-HBc-positive and anti-HBs-positive) before HSCT. But after HSCT or immunosuppression, HBV reactivation can also be observed in patients with previously resolved $\mathrm{HBV}$ infections [1, 2]. Our patient received entecavir to prevent $\mathrm{HBV}$ reactivation, and discontinued simultaneously with the cessation of immunosuppression.
Two months after entecavir withdrawal, she wasclinically suspected of having liver cGVHD based on her isolated AST/ALT elevation. She was then given a 40-day course of methylprednisolone $(8 \mathrm{mg} / \mathrm{d}$ for 10 days then $4 \mathrm{mg} / \mathrm{d}$ for a month) without antiviral prophylaxis. Her serum transaminase levels returned to normal. However, 6 months later, she had a high HBV DNA viral load and developed NS. The relationship between HBV infection and kidney damage is complex. HBV associated glomerulonephritis is a major extra-hepatic organ disease after HBV infection, however, not all patients with HBV infection have kidney damage associated with HBV but might exhibit HBV infection with primary glomerulonephritis [6]. The current diagnostic criteria for HBV associated glomerulonephritis include: 1) the presence of a serum HBV antigen; 2) the diagnosis of glomerulonephritis with the exclusion of other types of secondary nephritis; and 3) the presence of renal $\mathrm{HBV}$ antigen, which is required for the diagnosis of $\mathrm{HBV}$ associated glomerulonephritis $[6,12,13]$. In our case, we were unable to find evidence of HBV antigens in her kidney biopsy samples to prove conclusively that kidney damage was caused by HBV infection. Her renal biopsy also showed $\operatorname{IgA}, \operatorname{IgM}$ and $\mathrm{Clq}$ positive immunoflurescence staining in kidney tissues could indicate immunological abnormality was related to the development of NS.

HBVr combined with NS after allo-HSCT is a rare clinical problem. Its pathogenesis is not completely clear, so no clear treatment principles are currently available. In this case, we could notclarify the exact cause of NS, as the kidney biopsy findings are not specific for either HBV associated glomerulonephritis orcGVHD-related NS. Nevertheless, antiviral therapy combined withimmunosuppressive therapy gradually improved the outcome. Firstly our patient was administered entecavir to repress the replication of HBV DNA. Two months later, serum HBV DNA levels decreased more than 3 logs/ml but her renal function continued to deteriorate, which was consistent with there were no HBV antigens in her kidney biopsy samples. Since the kidney biopsy suggested immunological abnormality was related to the development of NS, immunosuppressants were then given to inhibit immune and inflammatory responses. After 2 years of antiviral and immunosuppressive therapy, she achieved complete remission of NS, but she still had microalbuminuria.

This case revealed thatreactivation of resolved HBV infectionshould be paid more attention after HSCT. There has been sporadic reports of $\mathrm{HBVr}$ in $\mathrm{HSCT}$ recipients with antibodies against $\mathrm{HBs}$ and $\mathrm{HBc}$ antigens, but the actuarial risk might be high $[1,2]$. Knoll et al. [14] monitored seven patients with pretransplant anti-HBs and anti-HBc antibodies and found that reverse seroconversion (from anti-HBs to HBsAg) was observed in six recipients. A previous study suggested that the absence of anti-HBs is a 
predictor of $\mathrm{HBVr}$ in patients with resolved hepatitis B receiving chemotherapy [15]. So, when our HSCT recipient's serum anti-HBs turned negative, we should have realized she was at high risk of $\mathrm{HBVr}$ and taken precautions to prevent it from happening. The current approach to preventing reactivation of resolved $\mathrm{HBV}$ infection is controversial. According to the guidelines of Asian-Pacific clinical practice guidelines on the management of hepatitis $\mathrm{B}, \mathrm{HBsAg}$ negative and anti-HBc positive subjects should be closely monitored by HBV DNA during and at least 12 months after immunosuppressive therapy and antiviral treatment should be started once the HBV DNA is detectable [16]. However, according to the guidelines of European association for the study of the liver, anti-HBc positive subjects undergoing stem cell transplantation, antiviral prophylaxis is recommended, and prophylaxis should continue for at least 18 months after stopping immunosuppression and monitoring should continue for at least 12 months after prophylaxis withdrawal [17]. The above guidelines both emphasize the importance of close monitoring. However, our patient did not undergo follow-up surveillance testing after she completed 40-day course of methylprednisolone, which revealed our deficiency in patient's education. Although HBV-associated liver disease after allo-HSCT is often temporary and not serious, fatal liver damage has been reported in some cases [18-20]. In our case, entecavir combined with immunosuppressive therapy could gradually improve the outcome of NS combined with HBVr. However, long-term immunosuppressive therapy can activate HBV replication and increase the risk of leukemia relapse; long-term antiviral treatment can lead to the emergence of drug-resistant mutant viruses. Therefore, closely monitoring and antiviral prophylaxis might both be necessary for HBsAg negative and anti-HBc positive patients undergoing HSCT.

In conclusion, entecavir combined with immunosuppression has efficacy in the treatment of $\mathrm{HBVr}$ combined with NS after allo-HSCT, but long course of treatment is needed. Closely monitoring and antiviral prophylaxis might be necessary for allo-HSCT recipients to prevent reactivation of resolved $\mathrm{HBV}$ infection and its related complications.

\begin{abstract}
Abbreviations
allo-HSCT: allogeneic haematopoietic stem cell transplantation; ALT: aminoleucine transferase; AST: aspartate aminotransferase; CGVHD: chronic graft versus host disease; GVHD: graft versus host disease; HBV: hepatitis B virus; HBVr: hepatitis B virus reactivation:

HSCT: hematopoietic stem cell transplantation; NS: nephrotic syndrome
\end{abstract}

\section{Acknowledgements}

The authors thank our patient for allowing us to write up her case and for her enthusiastic support throughout the process.

\section{Funding}

This work was supported by the Natural Science Foundationof Guangdong province, China (no. 2018A0303130248) and the Third Affiliated Hospital of Sun Yat-Sen University, Clinical Research Program (no. QHJH201806), and financial support in writing and publication of the manuscript.

\section{Availability of data and materials}

Data sharing is not applicable to this article as no datasets were generated or analyzed during the survey of this case. We used only information contained in the patient's clinical record. The medical file of the patient is available from the corresponding author on reasonable request.

\section{Authors' contributions}

$J W Z$ and XZZ prepared the manuscript and performed the literature search. XDL revised the. Manuscript. JWZ, XZZ, YLS, BL and XDL treated the patient. XZW cared for the patient. All authors read and approved the final manuscript.

\section{Competing interests}

The authors declare that they have no potential conflicts of interest to disclose.

Ethics approval and consent to participate

Not applicable, consent was obtained from the patient described in this report.

\section{Consent for publication}

Written informed consent was obtained from the patient for publication of this case report and any

accompanying images. Written consent is available by request.

\section{Publisher's Note}

Springer Nature remains neutral with regard to jurisdictional claims in published maps and institutional affiliations.

Received: 24 August 2018 Accepted: 7 January 2019

Published online: 16 January 2019

\section{References}

1. Knoll A, Boehm S, Hahn J, Holler E, Jilg W. Reactivation of resolved hepatitis $B$ virus infection after allogeneic haematopoietic stem cell transplantation. Bone Marrow Transplant. 2004;33(9):925-9.

2. Onozawa M, Hashino S, Izumiyama K, Kahata K, Chuma M, Mori A, Kondo T, Toyoshima N, Ota S, Kobayashi S, et al. Progressive disappearance of antihepatitis B surface antigen antibody and reverse seroconversion after allogeneic hematopoietic stem cell transplantation in patients with previous hepatitis B virus infection. Transplantation. 2005:79(5):616-9.

3. Lok AS, McMahon BJ. Chronic hepatitis B. Hepatology. 2007;45(2):507-39.

4. Michalak TI, Pasquinelli C, Guilhot S, Chisari FV. Hepatitis B virus persistence after recovery from acute viral hepatitis. J Clin Invest. 1994;94(2):907.

5. Ando M. An overview of kidney disease following hematopoietic cell transplantation. Intern Med. 2018;57(11):1503-8.

6. Peng T, Xie T, Liu L, Zhen J, Yang X. Analysis of clinical features and pathology of serum HBsAg positive glomerulonephritis. J Med Virol. 2018; 90(3):612-5

7. Momoki K, Yamaguchi T, Ohashi K, Ando M, Nitta K. Emergence of dipstick proteinuria predicts overt nephropathy in patients following stem cell transplantation. Nephron. 2017;135(1):31-8.

8. Luo XD, Liu QF, Zhang Y, Sun J, Wang GB, Fan ZP, Yi ZS, Ling YW, Wei YQ, Liu $X L$, et al. Nephrotic syndrome after allogeneic hematopoietic stem cell transplantation: etiology and pathogenesis. Blood Cells Mol Dis. 2011;46(2): 182-7.

9. Ikee R, Yamamoto K, Kushiyama T, Imakiire T, Suzuki S, Miura S. Recurrent nephrotic syndrome associated with graft-versus-host disease. Bone Marrow Transplant. 2004:34(11):1005-6

10. Brukamp K, Doyle AM, Bloom RD, Bunin N, Tomaszewski JE, Cizman B. Nephrotic syndrome after hematopoietic cell transplantation: do glomerular lesions represent renal graft-versus-host disease? Clin J Am Soc Nephrol. 2006;1(4):685-94.

11. Shulman HM, Kleiner D, Lee SJ, Morton T, Pavletic SZ, Farmer E, Moresi JM, Greenson J, Janin A, Martin PJ, et al. Histopathologic diagnosis of chronic graft-versus-host disease: National Institutes of Health consensus development project on criteria for clinical trials in chronic graft-versus-host disease: II. Pathology working group report. Biol Blood Marrow Transplant. 2006;12(1):31-47.

12. Ren J, Wang L, Chen Z, Ma ZM, Zhu HG, Yang DL, Li XY, Wang BI, Fei J, Wang ZG, et al. Gene expression profile of transgenic mouse kidney reveals 
pathogenesis of hepatitis B virus associated nephropathy. J Med Virol. 2006; 78(5):551-60.

13. Du W, Zheng Z, Han S, Ma S, Chen S. HBV reactivation in an occult HBV infection patient treated with prednisone for nephrotic syndrome: case report and literature review. BMC Infect Dis. 2013;13:394.

14. Knoll A, Boehm S, Hahn J, Holler E, Jilg W. Long-term surveillance of haematopoietic stem cell recipients with resolved hepatitis B: high risk of viral reactivation even in a recipient with a vaccinated donor. J Viral Hepat. 2007;14(7):478-83.

15. Yeo W, Chan TC, Leung NW, Lam WY, Mo FK, Chu MT, Chan HL, Hui EP, Lei $\mathrm{Kl}$, Mok TS, et al. Hepatitis B virus reactivation in lymphoma patients with prior resolved hepatitis $B$ undergoing anticancer therapy with or without rituximab. J Clin Oncol. 2009;27(4):605-11.

16. Sarin SK, Kumar M, Lau GK, Abbas Z, Chan HL, Chen CJ, Chen DS, Chen HL, Chen PJ, Chien RN, et al. Asian-Pacific clinical practice guidelines on the management of hepatitis B: a 2015 update. Hepatol Int. 2016;10(1):1-98.

17. EASL. 2017 clinical practice guidelines on the management of hepatitis $B$ virus infection. J Hepatol. 2017;67(2):370-98.

18. Nordbo SA, Skaug K, Holter E, Waage A, Brinch L. Reactivation of hepatitis B virus infection in an anti-HBC and anti-HBs positive patient after allogeneic bone marrow transplantation. Eur J Haematol. 2000;65(1):86-7.

19. Iwai K, Tashima M, Itoh M, Okazaki T, Yamamoto K, Ohno H, Marusawa H, Ueda Y, Nakamura T, Chiba T, et al. Fulminant hepatitis B following bone marrow transplantation in an $\mathrm{HBsAg}$-negative, $\mathrm{HBsAb}$-positive recipient; reactivation of dormant virus during the immunosuppressive period. Bone Marrow Transplant. 2000;25(1):105-8.

20. Sakamaki H, Sato Y, Mori SI, Ohashi K, Tanikawa S, Akiyama H, Sasaki T, Hiruma K. Hepatitis B virus reactivation in a patient with chronic GVHD after allogeneic peripheral blood stem cell transplantation. Int J Hematol. 2001; 74(3):342-6

Ready to submit your research? Choose BMC and benefit from:

- fast, convenient online submission

- thorough peer review by experienced researchers in your field

- rapid publication on acceptance

- support for research data, including large and complex data types

- gold Open Access which fosters wider collaboration and increased citations

- maximum visibility for your research: over $100 \mathrm{M}$ website views per year

At $\mathrm{BMC}$, research is always in progress.

Learn more biomedcentral.com/submissions 